\title{
Los fines de la formación universitaria desde una perspectiva de género
}

The aims of higher education from gender perspective

\author{
Enrico Mora / enrico.mora@uab.cat \\ MargotPujal / margot.pujal@uab.cat \\ Universitat Autónoma de Barcelona, España
}

\begin{abstract}
We present the main results of the analysis of the discourses that professors and students (by sex) have elaborated upon a set of university degree courses at the Autonomous University of Barcelona (Catalonia, Spain). We analyze, from a gender perspective, what kind of care and provision relationships are referred in such discourses. We identified a shared understanding between professors and students, independently from sex and degree, which emphasizes the provision like main end of the subjects. The incorporation of the dimension of care at weekends appears as a secondary aspect.
\end{abstract}

Key words: university professor, university student, social action, care, provision.

Resumen: Presentamos los principales resultados del análisis de los discursos que profesorado y alumnado (según sexo) han elaborado sobre los fines de un conjunto de asignaturas de titulaciones universitarias de la Universitat Autònoma de Barcelona (UAB) (Catalunya, España). Analizamos, desde la perspectiva de género, qué tipo de relaciones de cuidado y de provisión remiten dichos discursos. Identificamos una concepción compartida entre profesorado y alumnado, independientemente del sexo y de la titulación, que pone el acento en la provisión como principal fin de las asignaturas. La incorporación de la dimensión del cuidado en los fines aparece como un elemento secundario.

Palabras clave: profesorado universitario, alumnado universitario, acción social, cuidado, provisión. 


\section{Introducción}

En este artículo presentamos los principales resultados del análisis de los discursos que profesorado y alumnado elaboran sobre los fines de un conjunto de asignaturas de titulaciones universitarias de la Universitat Autònoma de Barcelona (UAB), Catalunya, España. El principal interés es identificar a qué tipo de relaciones de cuidado y de provisión remiten estos discursos y qué efectos tienen en la actividad socializadora de la formación universitaria.

Las nociones de cuidado y provisión han sido desarrolladas originariamente para analizar, desde una óptica feminista, la producción doméstica y la división sexual del trabajo. Constituyen un aspecto nuclear de la investigación en el campo de los estudios de género de las últimas décadas (véase, por ejemplo, Hochschild, 2012, 2008; Vega, 2009; Izquierdo, Mora y Duarte, 2008; Izquierdo, 2007; Torns et al., 2004; Ehrenreich y Hochschild, 2003; Fraise, 2000; Maruani et al., 2000; Sevenhuijsen, 2000; Setién, 1998; Bubeck, 1995; Jecker y Donnie, 1991).

Nosotras tomamos esas nociones para analizar un aspecto de la actividad académica del profesorado y del alumnado universitario que exponemos a lo largo de este texto. Nos planteamos qué hay de género (conceptualizado en nuestra investigación con las nociones de cuidado y provisión) en las actividades que desempeñamos como docentes en la universidad. Al mismo tiempo identificamos qué relación existe con el sexo (conceptualizado con las categorías mujer y hombre).

Para caracterizar el cuidado y la provisión desde el punto de vista del tipo de relaciones que establecen el profesorado y el alumnado en sus interacciones, nos apoyamos en el modelo de regímenes de relación de Boltanski (2000), en el modelo de Bubeck (1995), una de las pioneras en conceptualizar la noción de cuidado en el ámbito de los estudios de género, y la adaptación que de él hace Izquierdo (2007), una de las pioneras en los estudios de género y del sexismo en el ámbito universitario en España, entre otros campos.

En las interacciones que llevan a cabo las mujeres y los hombres se configuran relaciones de cuidado y/o de provisión. El cuidado es un tipo de relación social que se caracteriza por la acción de satisfacer las necesidades de una persona por parte de otra, donde la necesidad no puede ser satisfecha por la persona objeto de cuidado. La provisión se caracteriza por el predominio de las cosas y de la relación entre las personas y las cosas. Como fruto de la división sexual del trabajo, las mujeres han realizado habitualmente las actividades de cuidado y los hombres las de provisión, constituyéndose las primeras como actividades femeninas y las segundas como masculinas. 
A partir de estas premisas se focaliza la atención en un aspecto específico de la actividad docente universitaria: el análisis de los fines de la formación universitaria. Se trata de una aproximación novedosa, por qué habitualmente se ha llevado a cabo el análisis de las relaciones de cuidado y provisión en el campo de los estudios sobre el trabajo doméstico y la división sexual del trabajo. Asimismo, habitualmente el análisis de la actividad docente universitaria se ha realizado desde perspectivas pedagógicas con orientación o no de género, pero sin aplicar las nociones de cuidado y provisión al fenómeno objeto de estudio.

\section{Marco conceptual}

En la última década se ha producido un creciente interés en el estudio del impacto del sexismo y de las relaciones de género en el ámbito universitario. A pesar de ello, el tema no es nuevo. La llamativa ausencia de las mujeres en el campo académico, y especialmente en el científico y el tecnológico, ha sido señalada y documentada intensamente (Vázquez-Cupeiro, 2015; Rifa-Valls y Duarte, 2013; Duarte, 2012; Izquierdo, León y Mora, 2008; Fox, 2004, 1995; Izquierdo et al., 2004, 1999; Pérez y Andino, 2003; Rees, 2002; Fox y Stephan, 2001; ETAN, 2000; Clair, 1996; Ortiz y Becerra, 1996; Radl, 1996; González, Pérez y Fernández, 1995; Long y Fox, 1995; Van Verken y Hernández, 1989; Pérez Sedeño et al., s/f; Rossi, 1965).

Es un proceso que podemos identificar en buena parte del mundo occidental. Los cambios en el mundo académico de los últimos 50 años han pasado de una manifiesta exclusión entre el profesorado y entre el alumnado, a una importante incorporación de las mujeres en la universidad, pero caracterizado especialmente por la segregación (Osborn et al., 2000) tanto horizontal (campos de conocimiento) como por la vertical (la escasa presencia en las posiciones de mayor prestigio y reconocimiento académico, así como en los puestos directivos universitarios). Estos cambios son los que actualmente ocupan la agenda de investigación en el campo de los estudios de género aplicados al ámbito universitario.

Hoy en día disponemos de sólidos datos sobre los procesos de segregación sexual señalados. Sin embargo, no es suficiente identificar el sexismo para poder explicar las relaciones de género en Occidente. El sexismo es un proceso mediante el cual se forman a los seres humanos mediante una operación reduccionista que consiste en tomar una parte, los órganos procreativos, en representación del todo, la persona. Ese proceso reiterado mediante el recurso a prejuicios, estereotipos y modelos de acción constituye a los seres 
humanos en seres clasificados jerárquicamente, perfilando las subjetividades y posibles objetivaciones de las mismas.

La persona queda reducida a una de sus características, el sexo. Ese reconocimiento de un ser humano como "mujer" o como "hombre" no tiene otro fundamento material que las diferencias en los caracteres sexuales primarios, los directamente relacionados con la procreación (Izquierdo, 2001: 15). Ese fundamento es el primer acto de género. Con ello queremos decir que la construcción llamada "sexo" está tan culturalmente construida como el género. Es decir, siguiendo a Butler $(2001 ; 1990)$, no entendemos el género como la interpretación cultural del sexo, al entender que éste es ya una categoría dotada de género.

El género no debe concebirse sólo como la inscripción cultural del significado en un sexo predeterminado, también debe designar el aparato mismo de producción mediante el cual se establecen los sexos en sí. Eso quiere decir que el género no es a la cultura lo que el sexo es a la naturaleza. El género es también el medio discursivo mediante el cual la "naturaleza sexuada" o "sexo natural" se establece y se produce como "prediscursivo", previo a lo social (Butler, 2001).

Entonces el sexo no es un dato sensible, un rasgo físico que pertenece al orden natural. El hecho de que el pene, la vagina, los senos... sean denominados partes sexuales es tanto una restricción del cuerpo erógeno a esas partes como una fragmentación del cuerpo como totalidad (Butler, 2001; 1990; Wittig, 1981). Los "rasgos físicos" parecen en cierto sentido estar alli en el extremo lejano del lenguaje, no marcados por un sistema social. El "sexo" impone una unidad artificial a un conjunto de atributos que de otra manera sería discontinuo (Wittig, 1977). Y lo que vincula la construcción de los sexos en lo "hembril" y lo "machil" tiene que ver con la procreación de la especie y la constitución de la dictadura heterosexual. ${ }^{1}$

La capacidad de respuesta sexual del cuerpo es restringida por la institucionalización disciplinaria de la diferencia sexual binaria. En este contexto, Wittig (1977) se pregunta por qué no nombramos como rasgos sexuales a nuestras bocas, manos y anos... La respuesta que nos da es que únicamente nombramos sexual a los rasgos funcionales para la actividad procreativa.

Con ello no pretende Wittig negar la existencia de determinadas diferencias que son evidentemente binarias (en cuanto individuos sexuados de una especie). Lo que pretende es contestar a la práctica social de valorizar

1 Decimos dictadura porque se trata de una forma autoritaria de resolver el problema de la procreación. 
determinados rasgos anatómicos como si fueran definitorios no sólo del sexo anatómico sino de la subjetividad sexual. Señala que existen otros tipos de diferencias entre la gente, diferencias de forma y tamaño, de formación del lóbulo de las orejas y el tamaño de la nariz.

Sin embargo, cuando nace un bebé no preguntamos qué clase de lóbulo de las orejas tiene. Preguntamos inmediatamente por determinados rasgos anatómicos sexualmente diferenciados, porque suponemos que esos rasgos de algún modo determinarán el destino social de ese bebé, y ese destino, cualquiera que sea, es construido por un sistema de género predicado sobre la supuesta naturalidad de las oposiciones binarias y, en consecuencia, de la heterosexualidad. No discutimos la existencia o facticidad de las distinciones sexuales, sino que cuestionamos el aislamiento y valorización de determinados tipos de distinción por encima de otros (Butler, 1990).

Esto implica entender el sexo como una forma de acontecer del ser humano con su propia naturaleza, y por lo tanto, es incomprensible si se desliga de las prácticas sociales que históricamente afrontan, en primer término, la procreación de la especie. La procreación de la especie y la dictadura heterosexual van de la mano, y el análisis de los nexos de esos procesos sociales ofrece claves explicativas de la sociogénesis del sexo y de lo sexual como actos de género. En realidad, entender el sexo y la sexualidad como algo anterior a la ley es en sí la creación de la ley (Butler, 2001: 107).

En este sentido, estar sexuado significa estar sujeto a una serie de reglamentaciones sociales y mantener que la ley dirige esas reglamentaciones como formadoras del sexo, del género, de los placeres, de los deseos. La categoría sexo es inevitablemente reglamentadora (Foucault, 1998). Pero una reglamentación que organiza la desigualdad, la discriminación y la injusticia.

En este marco, someramente esbozado, situamos los conceptos de cuidado y provisión, como dimensiones de género del vínculo social en general y de la acción social en particular. Sostenemos que pueden ser unas herramientas de análisis útiles para poner en evidencia la dinámica de las relaciones de género y sus efectos. De forma específica, planteamos en este artículo su uso en un campo específico y focalizado: la docencia universitaria a través del análisis de los fines de las asignaturas. Con ello queremos contribuir a orientar los procesos de cambio hacia una universidad equitativa, señalando sus fundamentos de género para su mitigación.

Para definir los conceptos de cuidado y provisión partimos, como hemos señalado, de la propuesta de Boltanski (2000). En trabajos anteriores (Mora y León, 2011; Mora y Pujal, 2010; Mora, 2006; 2005) explicamos que la 
definición de cada régimen que elabora Boltanski (2000) tiene que ver, según nuestra interpretación, con preguntarse qué lugar ocupan en cada régimen las siguientes cuestiones, que nosotras presentamos como ejes de análisis de género de la acción social (apoyándonos en Hochschild, 2008; Orozco, 2007; Izquierdo, Mora y Duarte, 2008; Izquierdo, 2007; Ehrenreich y Hochschild, 2003; Mora, 2002; Thompsom, 2002; Butler, 2001; 1990; Dale y Jane, 2000; Sevenhuijsen, 2000; Setién, 1998; Jecker y Self, 1991 Bubeck, 1995; Wittig y Zeig, 1981): a) las necesidades de las personas; b) el logro del objetivo de la acción; c) las normas universales; d) los objetos en disputa; e) la existencia o no de relación entre las personas y las cosas en la acción, mediante un principio de equivalencia universal (estableciendo una escala de comparación), o mediante un principio de particularización en función de la persona (respondiendo a las necesidades específicas de cada una).

Bajo el cuidado, los objetivos de las acciones los constituyen las necesidades singulares de las personas, cuyo logro es condicionado por las necesidades de éstas, hasta el punto de que si cumplir con el objetivo se revelara contrario a esas necesidades en su ejecución, invalidaría la propia acción, modificándola o cancelándola. Bajo el cuidado, las normas que rigen las acciones están en función de las necesidades de las personas y no hay normas universales, caracterizándose el contexto de la interacción por la ausencia de objetos en disputa o en conflicto.

Del cuidado así entendido, podemos identificar dos formas específicas, en función de si existe o no relación entre las personas y las cosas en las acciones orientadas por el cuidado (las interacciones entre las personas bajo el régimen del cuidado pueden implicar sólo personas pero también la relación entre las personas y las cosas).

En el primer tipo de cuidado, el centrado en las personas, la acción está orientada a las necesidades de éstas, siendo su objetivo. Es decir, no hay un objetivo ajeno a la persona y sus necesidades. No hay un objetivo que se le impone, adapta u ofrece por parte de terceros que intervienen en la acción.

El objetivo es la persona misma, su inmediatez. En el segundo tipo de cuidado, el centrado en las cosas en función de las personas, la acción está orientada al logro de un objetivo (una cosa distinta de la persona), que no se desprende directamente de las necesidades de las personas y que se le ofrece o adapta por parte de terceros.

Sin embargo, la relación entre la persona y la cosa está condicionada por las necesidades de la destinataria de la acción. Dicha relación entre la persona y la cosa no es conflictiva, no hay disputa, se da por no problemática. En 
el momento en que dicha relación fuera tematizada como un problema, la orientación de la acción cambiaría al régimen de la provisión.

Una vez definido el cuidado, nos queda ahora la tarea de definir, aplicando los mismos ejes anteriores, la provisión. Bajo la provisión los objetivos de las acciones no atienden a las necesidades singulares de las personas, o si lo hacen es en términos instrumentales. El logro del objetivo de la acción es ciego a cualquier consideración ajena al propio objetivo. El objetivo es el fin. Para ello, el logro del objetivo se realiza en función de normas universales o por la fuerza. Bajo la provisión, el contexto de la interacción se caracteriza por la presencia de objetos en disputa y competencia.

De la provisión así entendida, podemos identificar dos formas específicas, en función de si existe o no relación entre las personas y las cosas en las acciones orientadas por la provisión (las interacciones entre las personas bajo el régimen de la provisión pueden implicar sólo cosas pero también la relación entre las personas y las cosas). En el primer tipo de provisión, la centrada en las cosas, la acción está orientada al logro de un objetivo ciego a las necesidades de las personas destinatarias de la acción.

El logro de ese objetivo, que es determinado de forma ajena a las personas, se antepone a las necesidades de éstas e incluso se le puede oponer. A pesar de ello, la acción que se orienta para alcanzarlo se lleva a cabo y no se modifica, a no ser por motivos instrumentales que permitan finalmente cumplir ese objetivo. El objetivo se debe lograr a cualquier precio, y el conflicto que implica hacerlo se resuelve, en última instancia, por la violencia.

En el segundo tipo de provisión, la centrada en la equivalencia entre las personas y las cosas, la acción está orientada al logro de un objetivo condicionado por principios universales. Mediante esos principios universales se establece una escala comparativa, o un orden de lo comparable, entre las personas y las cosas, de tal modo que el logro del objetivo queda subordinado a determinados criterios definidos de forma universal para las personas participantes de un determinado contexto de acción.

Dichos criterios regulan el conflicto que implica alcanzar el objetivo de la acción con la finalidad de condicionar el cumplimiento de éste. Bajo este tipo de provisión, el logro de los objetivos no se puede hacer a toda costa, pues su logro debe ajustarse a los criterios universales establecidos. Esta condicionalidad del logro del objetivo no se produce, por tanto, a raíz de que el objetivo entre en colisión con las necesidades de las personas singulares sino con las normas universales, cuya finalidad última es la de regular el conflicto o las disputas sin recurrir al empleo de la violencia. 
La relación entre las personas y las cosas son conflictivas y cuando logran ser resueltas de modo tal que se incorporan las necesidades de las personas de forma consensuada o estereotipada, dejan de estar bajo el régimen de provisión y entran en el régimen de cuidado.

Una vía de acceso al análisis del cuidado y la provisión en el contexto de los procesos formativos en la educación superior son los discursos que el profesorado y el alumnado elaboran al ser cuestionados sobre su experiencia en la vida universitaria. Analizamos las relaciones de cuidado y de provisión entre el profesorado y el alumnado que expresan las personas entrevistadas en sus discursos. Hay que tener en cuenta que un mismo sujeto puede expresar, en un mismo discurso, componentes de cuidado y de provisión. Pero, ¿qué efecto tiene expresar esta variedad de componentes en términos de un análisis que toma como variables independientes fundamentales el sexo y el género?

Un punto de partida es considerar que la orientación hacia el cuidado en la universidad es un rasgo predominante de las actividades que realizan las mujeres y de las titulaciones femeninas seleccionadas, y la provisión es un rasgo predominante de las actividades que hacen los hombres y de las titulaciones masculinas. Sin embargo, las evidencias apuntan algo distinto: la centralidad del logro del objetivo, de la singularización, de las normas universales, de los objetos en disputa en la orientación de las actividades entre profesorado y alumnado aparecen tanto en los discursos de las profesoras como de los profesores, tanto en los discursos de las alumnas como de los alumnos.

El elemento diferencial en términos de sexo y género está en la concreción sobre el objeto del que hablan. No podemos afirmar genéricamente que las mujeres cuidan y los hombres proveen en las actividades formativas universitarias. A ese nivel probablemente se produce lo que en estadística se conoce como el efecto de suma cero, donde las diferencias pueden llegar a desdibujarse por completo al agregarse demasiado los datos. Si tomamos un nivel de mayor detalle, fijándonos en contextos de acción particulares, como el de las asignaturas, y más aún, cuando hablan sobre los fines de las asignaturas, podemos identificar diferencias fundamentales entre mujeres y hombres, y entre las titulaciones. En las actividades formativas universitarias, mujeres y hombres de todas las titulaciones seleccionadas cuidan y proveen, pero no de igual modo, con intensidades variables y viviéndolo de forma distinta.

\section{Método: producción de datos}

Para elaborar este artículo nos hemos apoyado en la investigación "Cuidado y provisión: el sesgo de género en la prácticas universitarias y su impacto en 
la función socializadora de la universidad", dirigida por la Dra. María Jesús Izquierdo y financiada en convocatoria competitiva I+D por el Ministerio de Igualdad/Instituto de la Mujer. La perspectiva metodológica en la que inscribimos esta investigación es feminista y cualitativa. Una investigación conducida desde un marco feminista presta atención a temas como las diferencias-desigualdades y el cuestionamiento de las relaciones de poder social entre sexos y géneros.

Asimismo, recupera la capacidad de resistencia a la versión tradicional y sexista sociocientífica y se compromete con el activismo político, la justicia social y la profundización democrática. La metodología cualitativa nos permite comprender los fenómenos sociales mediante los significados que las propias personas participantes aportan. De manera más específica, construimos la aproximación cualitativa a través de la metodología del análisis del discurso. Los fundamentos teóricos, epistemológicos y las características técnicas de esta metodología posibilitan: comprender e interpretar la realidad social y su construcción discursiva; acceder a los procesos, acciones, procedimientos y prácticas; analizar de forma detallada y específica nuestro objeto de investigación para identificar las cadenas de significados y acciones que lo rigen.

El estudio se centra en la Universitat Autònoma de Barcelona, y el trabajo de campo concluyó en 2008. Los criterios fundamentales para seleccionar a las personas por entrevistar han sido, en cuanto a la posición ocupada en la institución universitaria, el profesorado y el alumnado, según sexo y curso (primer curso y último curso). En cuanto a la elección del conjunto de titulaciones estudiadas, hemos seleccionado en función de la posición que ocupan las titulaciones respecto a la orientación de género. Para ello hemos tomado la definición del plan de estudios de cada titulación realizada por las autoridades académicas, así como la composición según el sexo del profesorado y alumnado de las titulaciones.

El primer aspecto nos permite clasificar las titulaciones según sus competencias formativas ubicándolas en las categorías cuidado-provisión, ateniendo el marco conceptual señalado anteriormente. El segundo aspecto remite a la situación de las titulaciones respecto del eje feminización-masculinización (grado de sexismo). Como variables indicativas del grado de masculinización o feminización de una titulación, tomamos el porcentaje de mujeres entre el profesorado y alumnado (consideramos que una titulación está feminizada o masculinizada si el alumnado y el profesorado están compuestos por más del $60 \%$ de mujeres u hombres, respectivamente). 
El resultado, para la UAB en el periodo estudiado, ha sido el de centrarnos en las siguientes titulaciones: Magisterio, Especialidad en Educación Infantil; Pedagogía; Relaciones Laborales; Derecho; Ingeniería Técnica Informática de Sistemas; Ingeniería Informática. Los resultados que presentamos derivan de la realización de un total de 45 entrevistadas en profundidad, 22 a docentes (11 profesoras y 11 profesores), y 23 a estudiantes (11 alumnas y 12 alumnos). Tomamos como criterio principal de selección del profesorado y del alumnado que lo fueran de una asignatura troncal/obligatoria de las titulaciones indicadas, de primero y de último curso.

La decisión de hacer entrevistas en profundidad responde al objetivo de recoger la experiencia transmitida a quien investiga mediante la conversación con las personas informantes. Este encuentro obedece al objetivo de comprender la perspectiva que tienen dichos informantes en relación con sus vidas, experiencias o situaciones, el sentido que dan a sus actos o a su experiencia (Ruiz e Ispizua, 1989; Taylor y Bogdan, 2000). Las entrevistas fueron grabadas (con permiso de las personas entrevistadas) y transcritas literalmente, conservando el anonimato de los informantes.

En cuanto a las técnicas de análisis de los datos, hemos optado por el de contenido y el crítico del discurso. El análisis de contenido pretende organizar la información con base en categorías emergentes de la interpretación de los datos (Vázquez, 1996), y se realizó a nivel textual (creación de citas y códigos) y a nivel conceptual (elaboración del análisis para relacionar conceptualmente las citas y los códigos).

En cuanto al nivel textual, segmentamos el texto en citas y lo codificamos para facilitar la recuperación y reelaboración posterior de la información con otros niveles de análisis. En cuanto al nivel conceptual, vinculamos los códigos emergentes del texto con nuestro marco teórico, y al mismo tiempo derivamos de la elaboración teórica conectores que permitieran establecer relaciones analíticas entre códigos.

El análisis del discurso pretende la localización de relaciones de poder entre posiciones determinadas (Iñiguez, 2005). En concreto, aplicamos el análisis crítico del discurso (Martín, 2003). Esta línea concibe al discurso como práctica social, lo que cuestiona su consideración como práctica descriptiva / representativa (Potter y Wetherell, 1987; Parker, 1992). Apunta a la existencia de una realidad extra discursiva material en la cual se establecen relaciones de poder y dominación que en parte son reflejadas y conformadas por el mismo discurso. 


\section{Los fines de las asignaturas}

De la variedad de contextos donde interactúan profesorado y alumnado, el que les vincula por excelencia es el de las asignaturas. Es donde se relacionan de manera más explícita. En términos generales, las asignaturas vendrían a ser el ámbito principal donde se lleva a cabo una de las finalidades fundamentales de la universidad: la formación. En el Artículo 4. Finalidades (Estatuts de la Universitat Autònoma de Barcelona, 2003) se establece este fin en los siguientes términos:

a) Ejercer la docencia de grado superior, tanto respecto del conocimiento y la cultura como de la formación especializada y la preparación para el ejercicio profesional, con un espíritu de prosecución constante de la calidad y la excelencia. [...]

e) Participar en la mejora y en el desarrollo del sistema educativo. [...]

g) Fomentar el pensamiento crítico, el espíritu emprendedor y la cultura de la libertad y el pluralismo, así como la educación en los valores cívicos y sociales propios de una sociedad democrática.

h) Difundir la cultura a través de actividades de extensión universitaria y de formación permanente a lo largo de la vida de las personas. [...]

La formación es un aspecto central de la actividad universitaria dedicando cuatro de los nueve fines que establecen los estatutos (el resto se dedican a la investigación, la gestión y la evaluación de la calidad, que no reproducimos en la cita), siendo el primero de todos ellos dedicado a la docencia. Desde el punto de vista formal, la universidad expresa como objetivo prioritario de su actuación su función formativa en términos cognitivos: epígrafe $a$ ) y $b$ ); pero también éticos y morales: epígrafe $g$ ); así como incidir en la forma en cómo se llevan a cabo esos objetivos: epígrafe $e$ ).

Si leemos estas finalidades según la centralidad de las personas y/o de las cosas que pueden contener implícitamente, y a riesgo de simplificar en exceso, todas las finalidades estarían orientadas particularmente a señalar como objeto de la docencia el vínculo entre las personas y las cosas. Indican un conjunto de cosas que podríamos agrupar en conocimientos de calidad, habilidades y valores políticos sociales que se vinculan con las personas a través de, principalmente, dos principios que debe atender toda la comunidad universitaria y en particular el profesorado y el alumnado: la formación en el ejercicio profesional y la formación ética y moral de las personas.

Por lo tanto, la orientación de las finalidades de la universidad, en cuanto a la formación se refiere, podemos interpretarla en términos de provisión centrada en la equivalencia entre personas y cosas, donde los principios que 
permiten vincular las personas y las cosas son, por un lado, las salidas profesionales de las titulaciones, y por el otro, la formación de las personas como ciudadanos democráticos y emprendedores, fomentando el pensamiento crítico.

Ambos principios funcionan como principios universales, comunes para toda la comunidad universitaria, desatendiendo los extremos de las relaciones de cuidado y provisión: ni forma parte de los fines prioritarios y declarados de la universidad atender las necesidades particulares de los individuos que la componen ni supeditar a las personas al logro a toda costa de los objetivos.

Si dejamos este nivel declarativo institucional y nos adentramos en el contexto restringido de las asignaturas, ¿cómo se expresan estas finalidades? La pregunta es pertinente: por qué si sostenemos que es el ámbito por excelencia de la actividad formativa universitaria y del vínculo entre profesorado y alumnado, las finalidades que las personas entrevistadas asocian a las asignaturas pueden indicarnos hasta qué punto son concebidas en términos de cuidado y/o provisión las relaciones que ahí despliegan.

A partir de lo que expresan las personas entrevistadas sobre la utilidad de las asignaturas, la formación recibida para la actividad profesional, el impacto de la formación a nivel personal y las expectativas sobre la formación en la universidad, derivamos qué tipo de objetivos asociados a la formación se señalan.

\section{La provisión como dimensión transversal de los objetivos de la formación universitaria}

En términos generales, el profesorado entrevistado expresa una concepción provisora de lo que cabe esperar de una asignatura. Las asignaturas que imparten tienen por objetivo común el de contribuir a dar una salida profesional al alumnado. Sirve para conseguir con mayor facilidad un empleo, desarrollar una profesión o incluso montar un negocio propio.

En este sentido, habría una coherencia notable entre los fines institucionales, recogidos en los estatutos de la propia universidad, y los niveles discursivos más concretos. No se trata de un dogma o una consigna institucional aplicada de forma mecánica por el profesorado. Más bien parece una evidencia que atiende a las necesidades que las propias personas, en este caso, el alumnado, expresan y reclaman.

Así, lo que da sentido a los conocimientos que se adquieren es su adecuación al mercado de trabajo. Y este principio es el que permite poner en 
relación esos conocimientos con las personas. Responde a un principio que homogeniza las particularidades: las exigencias del mercado. Esta forma de concebir los fines es la más transversal de todas si atendemos al sexo, la titulación, el tipo de titulación (diplomatura o licenciatura) y el colectivo de las personas entrevistadas. En cambio, tener como fines el conocimiento en sí mismo, o que responda a las necesidades particulares de cada estudiante en concreto son objetivos sectoriales (sobre ello volvemos más adelante).

$\mathrm{P}:$ ¿Crees que le será útil a tus alumnos?

$\mathrm{R}: \_$La asignatura?

P: Sí.

R: Sí, es esencial. Es muy útil.

P: ¿̨or qué?

R: Bueno, primero, el tema de las redes, es que hoy en día tienen que saber qué está pasando detrás de la máquina. Se conectan a internet. Qué problemas puedes tener por estar conectado. En casa ya no tienes sólo un ordenador. Probablemente tienes tu ordenador, el de tu marido, el de tu hijo. Ya tienes una pequeña red. Tienes que saber todo lo que está pasando. Y además en las prácticas procuramos introducirlos en un lenguaje de última generación que seguramente utilizarán en la empresa privada. Yo estoy, yo estoy súper convencida de que es una asignatura que les va a ayudar mucho.

P: ¿Por qué les das una perspectiva?

R: Sí, porque primero les explicas qué está pasando detrás de aquella máquina que está conectada a un cable, y eso lo tienen que saber, para entender cuando hay problemas por qué están pasando esos problemas.

$\mathrm{P}: \mathrm{Mm}$.

$\mathrm{R}$ : $\mathrm{Y}$ aparte de eso, que es la parte de la asignatura más teórica, en la parte práctica les hacemos hacer prácticas relacionadas con las redes, pero utilizando lenguajes de programación que seguro, seguro, utilizarán en la empresa privada, y que no se les ha enseñado antes. Nosotros ya nos informamos de qué han hecho en otras asignaturas, miramos qué hacen en otras asignaturas por no

P: [corta] solapar, repetir.

R: Exacto. Y estos lenguajes no los conocían y decidimos amoldarlos a nuestras prácticas para que los viesen. Porque cuando lleguen a la empresa privada. Vale, que tal vez se despistan y que no han aprendido y no lo han asimilado todo, pero muchas cosas sí, claro. Les ayuda a ir mucho más rápido, y se están adaptando a lo que encuentran en la empresa privada. Porque a fin de cuentas, lo que ellos tienen que saber es dónde tienes que buscar la información, adquirir los conceptos básicos que te ayuden a razonar y acabar de entender todo lo que hay detrás.

(Reg. 495-506. Entrevista 19p: profesora de último curso de Ingeniería Técnica en Informática de Sistemas). 
La entrevistada vincula los contenidos de la asignatura con la utilidad que tienen en la actividad profesional, especialmente su adecuación en la empresa privada (que nombra recurrentemente). En ello hay un principio latente mediante el cual se valoran las cosas y que es el de considerar si una asignatura es fundamental o no en función de si es útil o no. Pero una utilidad definida en términos heterónomos, es decir, definida apelando a principios ajenos a la dinámica interna académica: las reglas del mercado. Es a partir de ese objetivo como se organizan los contenidos y las habilidades de un modo eficiente que evite redundancias o vacíos en el conjunto de las asignaturas de la carrera.

Sin embargo, cabe preguntarse si una atención prioritaria a la adecuación de los fines de las asignaturas al mercado implica situarse en un plano exclusivamente provisor. Si atendemos sólo a la relación entre los fines de las asignaturas y las necesidades de las personas que expresamente se quieren cubrir, parecería que sí: el alumno y la alumna aparece como un futuro empleado o empleada de una empresa privada. Pero si nos despegamos de este nivel, podemos identificar un efecto que vincula esta concepción de los fines con una concepción más próxima al cuidado.

A pesar de que los fines están asociados al mercado de trabajo, y por lo tanto se explican unas cosas y no otras, se desarrollan una competencias y no otras, hay un implícito, paradójico: ponerse como objetivo preparar el alumnado para el mercado de trabajo implica ayudarles a desarrollar el principio de realidad y su autonomía, aspectos estrechamente ligados con las prácticas de cuidado. Se trataría de un efecto, que en la mayoría de los discursos no se explicita como un fin buscado.

Si se nos permite el juego de palabras, se estaría cuidando mediante la provisión. Parecería, a través de sus discursos, que el profesorado se propone un fin genérico, próximo al cuidado, que es el de atender a lo que le va a hacer falta al alumnado, pero su concreción, paradójicamente, pasa por formular fines atentos a principios de equivalencia, atendiendo al mercado y no a las voces singulares de cada alumno y cada alumna.

Como hemos señalado, la salida profesional es, al mismo tiempo, el común denominador con las concepciones que expresa el alumnado. De algún modo, cada asignatura es evaluada por parte del alumnado en función del grado en que se adecua a ese principio. En este punto, el profesorado ofrece provisión y es lo que espera el alumnado, pero una provisión ajustada a principios de equivalencia. Las relaciones que se establecen en la asignatura parten de una orientación genérica, de fondo, que es el logro del objetivo, pero un objetivo sometido al principio de las exigencias profesionales que marca 
el mercado, objetivado en el título, el cual ofrecerá mayores oportunidades de trabajo y mejores condiciones.

P: ¿Tú qué esperas de la universidad?

R: Estar más preparado de lo que estoy ahora para el mundo laboral, adquirir unos conocimientos. Y también, en parte, tener un título que, seguramente con el título éste cobraré mucho más que con lo que tengo ahora. Eso es lo que yo creo.

(Reg. 11540-11541. Entrevista 17a: alumno de primer curso de Ingeniería Técnica en Informática de Sistemas).

No sabemos si esto es efectivamente así. Tampoco podemos descartar que lo que expresan las personas entrevistadas puede ser una forma de legitimar el conocimiento que se imparte o se aprende (al fin y al cabo poder evaluar hasta qué punto un conocimiento en particular es útil o no para trabajar es algo bastante difícil de precisar y sobre lo cual no hay muchas evidencias empíricas). Sin embargo, lo que interesa aquí es poner de manifiesto que lo que de entrada se expresa es un relación sometida a una racionalidad instrumental (se trata de una racionalidad que ha colonizado cada vez más el mundo de la educación, como ya señalaron Curráis Porrúa y Pérez-Froiz, 1995; Schön, 1992; Contreras, 1990; Giroux, 1990).

La racionalidad instrumental que expresan las personas entrevistadas consiste en asignar a las asignaturas en particular y a las carreras en general unos fines, las salidas profesionales, como fines evidentes, como algo que debe lograrse porque sí. Es decir, prácticamente ninguna persona entrevistada argumenta por qué debe perseguirse ese fin, por qué es tan importante, por qué, en definitiva, es deseable (Horkheimer, 2002).

Es una realidad obvia, estereotipada. En este sentido no se someten a crítica los fines que se persiguen, por eso el objetivo común más amplio y generalizado entre las personas entrevistadas independientemente del sexo, titulación y colectivo, que es contribuir a dar salidas profesionales, es también el menos reflexivo entre las personas entrevistadas.

En esta relación instrumental, el profesorado es construido como fuente de provisión de conocimientos útiles para el mercado y el alumnado como receptor de dicha provisión que demanda como tal. Esto no quiere decir que no haya atisbos de inquietud en torno a ese objetivo, pero formulados, básicamente, como la paradoja anteriormente señalada, o en términos de eficacia: ¿se logra el objetivo?

El alumnado, especialmente de último curso, expresa cierto escepticismo sobre si efectivamente lo que se espera, la salida profesional, se cumpla. Y por 
parte del profesorado, si bien manifiesta la importancia de ofrecer conocimientos útiles para el desarrollo profesional, sabe que está bajo la sospecha de que efectivamente no sea reconocida esa utilidad por parte del alumnado. Quizá lo que mejor señala esta disputa que preside de manera genérica y difusa la actividad formativa es cuando se expresa que no se espera nada de la formación, incluida la salida profesional.

R: ¿QQué espero de la universidad...? Nada, no espero nada. ¿De la institución quieres decir?

P: Sí.

R: No, no espero nada.

$P$ : Una pizca en general.

R: No, no espero nada de la universidad. No creo que... nadie te abra las puertas ni nadie... A ver... aporta mi título universitario, pero la universidad en sí no... no espero nada.

(Reg. 15977-15981. Entrevista 3a: alumna de último curso de Maestro. Especialidad en Educación Infantil).

Y si alguien no espera nada de su formación universitaria, ¿̇a qué va entonces? Es relevante que quien hace esta afirmación es una alumna de último curso. Quizás expresa un duelo. El fin de una etapa y el inicio de otra llena de incertidumbres que parecen difíciles de controlar. Quizás apunta a un cambio en la posición de sujeto: pasar de que te abran las puertas a abrirlas, y ante la disyuntiva, el abismo de la nada.

\section{Del cuidado a la provisión en los objetivos de la formación universitaria}

El denominador común entre el profesorado y el alumnado que hemos señalado, la salida profesional, parecería indicar que no hay una influencia clara del sexo, de las titulaciones y del colectivo de quienes hablan. Las cosas son distintas si atendemos a otros objetivos expresados. Los objetivos de las actividades formativas centrados en las cosas y los objetivos centrados en las personas están diferenciados según el sexo, la titulación y el colectivo. Las profesoras de las titulaciones de Magisterio, Pedagogía y Relaciones Laborales no expresan ninguna finalidad centrada en las cosas y su logro; más bien indican objetivos centrados en las personas (aparte de los fines vinculados con las salidas profesionales, ya comentados).

$\mathrm{P}:$ ¿Y consideras que será útil a tus alumnos esta asignatura?

R: Yo considero que será útil. Mis alumnos a veces no saben por qué les será útil. Yo 
intento, como te decía antes, trabajar elementos. A mis alumnos cuando llegan el primer día les pregunto qué expectativas tienen y me dicen cosas como vinculadas al desarrollo personal, a la libre expresión, tener un ámbito de evasión dentro del currículo, etc. Se encuentran una asignatura (-) que yo lo que intento es que la cultura visual, las imágenes y las disciplinas que pertenecen a la cultura visual, la historia del arte, los estudios culturales, la educación artística, etcétera, etcétera, les sirvan para ser unas personas que puedan trabajar críticamente con la imagen, para comprender críticamente los entornos visuales, e intento coger la niñez como tema llave, ¿no? Creo que les será muy útil como educadoras del ciclo infantil. Poder pensar en qué imágenes trabajar cuando trabajen con niños, porque realmente las aulas de infantil son espacios muy, muy visuales, ¿no? También intento que puedan entender el ámbito de la educación artística como un ámbito históricamente construido. Es decir, que las alumnas no sean reproductoras de las prácticas que recibieron ellas. [Las alumnas] son gente de tarde, por lo tanto puedo tener gente que fue a la escuela infantil hace veinticinco años, y que vienen deseando hacer las prácticas de educación artística que hicieron hace veinticinco años, sin entender por qué esos tipos de prácticas pertenecen a un modelo de currículo, pertenecen a una visión de la educación artística franquista, de antes de la ley del mil novecientos setenta, ¿no? entonces intento sobre todo la primera parte del curso, dedicada al de desarrollo del pensamiento del profesor, que piensen críticamente en todo eso, desde una vertiente mucho más cultural, y también desde una vertiente mucho más de lo que es nuestro ámbito curricular. A ellas les cuesta ver para qué les sirve, porque no les explico cosas directamente de aplicación en aula, y no les doy una receta directamente, les cuesta. Entonces hay todo un trabajo de que entiendan por qué es importante desarrollar el pensamiento crítico del profesor, por qué se tienen que formar ellas también y no sólo les hemos de decir cosas sobre los niños, también les tenemos que decir cosas sobre ellas, ¿no? Hablo de ellas porque es una clase mayoritariamente de chicas, entonces por eso te digo, yo tengo muy claro de que les sirve, ahora, hablarás con ellas y, de hecho, uno de los métodos de evaluación ha sido una entrevista personal, y lo que he localizado es esta duda de "ha sido muy interesante, pero, de qué nos servirá como educadoras, eso, ¿no?” (-) Lo van descubriendo, ¿eh?, también, a final del curso la asignatura continúa, pero sí que nos movemos en este dilema.

(Reg. 3874-3877. Entrevista 1p: profesora de primer curso de Maestro. Especialidad en Educación Infantil).

Más allá de las referencias a la utilidad profesional de la asignatura que menciona la entrevistada, en este fragmento podemos identificar elementos de cuidado al señalar la entrevistada que quiere formar a las alumnas en cuanto tales y no sólo enseñarles cosas sobre el objeto de la asignatura, las niñas y los niños. Parece indicar que el objetivo de la asignatura es incluir en el contenido también a las propias alumnas.

No se trata sólo de saber unas determinadas cuestiones sobre la educación artística, sino elaborar un discurso que también les afecte a ellas mismas. 
Hasta qué punto la singularización afecta a los contenidos no lo sabemos, pero en todo caso podemos afirmar que forma parte de los contenidos poder singularizarse en cada alumna. Esa voluntad de singularización se manifiesta en el hecho de que la profesora a la que nos referimos realiza exámenes orales.

Quizá podríamos decir que el cuidado aparece en los contenidos en la forma de querer impactar en la reflexividad de la alumna. Quizá se está expresando como un fin incidir en la formación moral del sujeto, y este aspecto en las titulaciones masculinas no se expresa. Asimismo, este fin parece generar algún tipo de tensión o conflicto con el alumnado, lo cual obliga a explicarlo y argumentarlo, y señala como lo que es definido como una necesidad del alumnado por parte del profesorado no coincide necesariamente con lo que el alumnado demanda.

Desde el punto de vista del tipo de relación al que se apunta, se alejaría de una racionalidad instrumental de los fines. Parecería que aquello vinculado con fines centrados en las personas no estaría sometido a una concepción dada por descontado. Requeriría explicitar por qué son deseables y, por tanto, su posible crítica. En este sentido parecería que un fin de este tipo no es algo ni esperable ni obvio en la actividad formativa universitaria. Otra forma de introducir en los fines a las personas y sus necesidades es señalando qué tipo de necesidades la asignatura puede ayudar a satisfacer:

P: ¿Consideras que les será útil a tus alumnos y alumnas?

R: Yo creo que sí. Yo creo que sí, una cosa es que les sea útil y otra cosa es que les guste.

P: Ya. (ja ja)

R: (ja) Esto nos ocurre a todos con los temas que vamos estudiando. Pero siempre les digo el primer día que la Seguridad Social es algo que nos acompaña a lo largo toda la vida. Calcular alguna prestación... algún familiar le va a preguntar cómo se va a jubilar y cuánto va a cobrar, o ellos mismos si se van a plantear en algún momento si se quedan sin empleo, cuánto van a cobrar y si van a tener derecho al desempleo o no. Con lo cual tiene una perspectiva práctica. Es una asignatura que nos va a perseguir. Luego, hay partes más divertidas, más aburridas. Pero útil, sí.

(Reg. 1195-1198. Entrevista 11p: profesora de último curso de Relaciones Laborales).

La utilidad está en el tipo de atención que puedes dar a las personas próximas y a una misma (expresado a través de los ejemplos), al poder atender sus dudas y ayudarles. Pero en este caso, el cuidado expresado consiste en situar el conocimiento, la seguridad social, en función de las personas. Las finalidades de la asignatura expresadas en esta cita no consisten en aprender la materia en sí misma, o para lograr una salida profesional, sino para ayudar, afirma la entrevistada, a los familiares y a uno mismo, y por lo tanto introduce 
en la forma en que da sentido a la asignatura, la singularización en las necesidades de personas que son particularmente importantes para el alumnado.

En cambio, aparte de los fines vinculados con las salidas profesionales (ya comentados), las profesoras de Derecho, Ingeniería Técnica Informática de Sistemas, e Ingeniería Informática indican como finalidades centradas en las cosas lograr el aprendizaje de unos conocimientos que se deben saber en sí mismos y prácticamente ninguno centrado en las personas, bajo la expresión de una racionalidad instrumental que no somete a crítica estos fines (algo común con los profesores).

$R: A$ ver, yo te digo lo que espero. Que aprendan a pelearse con esas herramientas, es un poco genérico, pero que aprendan a buscar por internet a cómo solucionar problemas que se van a encontrar. A ver, está orientado a gente que va a programar. Si luego te conviertes en un directivo, pues ya no. Pero eso, cómo solucionar problemas informáticos de programación, a lo largo del proceso de creación de software.

(Reg. 1478. Entrevista 23p: profesora de último curso de Ingeniería Informática).

Lo que se propone la profesora es lograr que las y los estudiantes sepan resolver problemas técnicos. Problemas entendidos como cosas con las cuales se entra en confrontación, como una naturaleza que debe doblegarse incluso usando la violencia, en este caso, una naturaleza informática que debe someterse.

Así pues, en cuanto a finalidades se refiere, las profesoras de las titulaciones más próximas a lo femenino cumplen con la expectativa de género asignado socialmente a su sexo, al prestar atención especialmente a las personas. Mientras, las profesoras de las titulaciones más próximas a lo masculino rompen con la expectativa de género asignado a su sexo al adoptar como finalidad objetivos centrados en las cosas, es decir, en priorizar el aprendizaje de los contenidos.

Esto parecería señalar que el género de las titulaciones incidiría más que el sexo sobre el profesorado, hasta el punto de disciplinar el profesorado en el género de la titulación. ¿Pero esto es así para los profesores? En este caso no es tan evidente. Los profesores de Derecho, Ingeniería Técnica Informática de Sistemas, e Ingeniería Informática cumplen con la expectativa de género asignado a su sexo al adoptar como finalidad objetivos centrados en las cosas (aparte de los fines vinculados con las salidas profesionales, ya comentados).

P: ¿Qué habilidades crees que adquiere el alumnado a través de esta asignatura?

R: Fundamentalmente el conocer la mecánica, la estructura, pero sobre todo el funcionamiento práctico del proceso, de cómo se desarrolla un proceso civil, un proceso pe- 
nal, sus distintas variedades. Qué tiene que hacer un señor si tiene una letra de cambio para ejecutarla. Qué procedimiento debe elegir y cómo funciona ese procedimiento.

P: Aparte del conocimiento, ¿qué habilidades aprende a desarrollar o a poner en práctica?

R: En principio ninguna especial. Simplemente el conocimiento de cómo funciona, es un poco el inconveniente, el reverso de la medalla, el inconveniente de lo que hablaba antes, que es una enseñanza muy práctica y sin excesivos fundamentos teóricos o explicativos o filosóficos. Incluso introduciendo bastantes elementos de lo que se llama sociología del derecho, no de cómo el derecho debería funcionar, sino cómo funciona en la práctica.

P: Por lo tanto, ¿no se aprenden estrategias, formas de...?

R: No.

P: Es una información que después no implica una habilidad concreta.

R: Exactamente. Esto se deja a otras asignaturas. Hay un practicum, por ejemplo, que es donde esto se desarrolla. Nosotros nos limitamos a explicar el funcionamiento del proceso y a hacer mucha exégesis de los textos legales, de cómo hay que entenderlos, la jurisprudencia en general.

(Reg. 4172-4179. Entrevista 16p: profesor de último curso de Derecho).

El entrevistado centra el objetivo en el aprendizaje y adquisición de conocimientos e información, hasta el punto de expresar que todo aquello relacionado con el aprendizaje de habilidades quedaría para otras asignaturas. El énfasis en el objetivo de aprender la estructura y proceso del procedimiento legal en términos estrictamente de cosa se expresa incluso tomando como cosa a las personas que intervienen en dicho proceso.

Así, el señor del que habla en el ejemplo, no lo es en tanto persona cuyas necesidades particulares hay que atender, sino que es una pieza más de la mecánica procesal que debe conocerse y saber ubicar en su lugar. Esto no nos debería hacer creer que todos los objetivos de las asignaturas centrados en las cosas se remiten exclusivamente al aprendizaje del contenido en sí mismo. En algunos casos se introduce un matiz que refuerza aún más la prioridad de este tipo de objetivos. Aparte de querer suministrar unos conocimientos e informaciones, se propone cambiar el concepto que los estudiantes tienen del contenido a aprender.

Así, por ejemplo, en el caso de Informática, este objetivo consiste en pasar de una concepción particular de la informática como usuario singular (habiendo tantos posibles usos e intereses como personas), a un concepto científico y tecnológico, caracterizado por la estandarización y racionalidad compartida, un objetivo esperable al estar estudiando una ingeniería informática. Este fin constituye un objetivo de tipo procesal que pretende hacer transitar el alumnado de lo particular a lo general. 
Se trata pues de un objetivo que busca desingularizar al alumnado probablemente como contrapeso a un perfil de éste cuyos conocimientos previos a la carrera han sido formados en respuesta a las necesidades de uno mismo, siendo por definición un conocimiento parcial, particular y limitado. La importancia que le da el entrevistado a este objetivo se puede ver en el coste que está dispuesto a asumir: la pérdida y desmotivación del alumnado.

No ocurre lo mismo para las titulaciones más próximas a lo femenino. Las personas entrevistadas de estas titulaciones expresan objetivos que se refieren tanto a las relaciones de cuidado como a las de provisión, a diferencia de las masculinas, en las cuales, a excepción de un caso, todos los objetivos expresados se refieren a las relaciones de provisión.

En este sentido parecería que las titulaciones femeninas no tienen el mismo impacto en los hombres que las titulaciones masculinas en las mujeres. Dicho de otra manera, no disciplinarían del mismo modo, hasta el punto de que en el caso de las profesoras parece obedecer básicamente al género de las titulaciones en cuanto a fines formativos, sin apenas diferencias si se trata de diplomaturas o de licenciaturas, y en el caso de los profesores a los imperativos de su sexo.

En el caso de las profesoras, si expresan objetivos centrados en las cosas es, a riesgo de simplificar, porque caracterizan a la titulación, mientras que si lo hacen los profesores se debe a que es algo que caracteriza a la posición de género de los hombres. Una posible interpretación es entender que el género de la actividad formativa universitaria es, en su nivel más general, masculino.

Simpson (2004) ha explicado algo similar en su análisis de los hombres que trabajan en ámbitos femeninos y de las mujeres que trabajan en ámbitos masculinos. En este caso tampoco se produce una situación simétrica. Señala que los hombres son bienvenidos en los ámbitos femeninos y se espera de ellos que actúen como hombres (reconociéndose implícitamente que faltan sus cualidades en la profesión); mientras que las mujeres no son ni tan bienvenidas ni se espera que actúen como mujeres (reconociéndose implícitamente que no faltan sus cualidades en la profesión). En pocas palabras, ellos reafirman su masculinidad, ellas se masculinizan.

Así pues, en términos generales la diferencia entre las titulaciones femeninas y las masculinas es que las profesoras no expresan siempre objetivos vinculados al cuidado, sino sólo en aquellas titulaciones más próximas a lo femenino. En tanto, los profesores siempre expresan objetivos vinculados a la provisión en todas las titulaciones. Sin embargo, hay dos matices que limitan esta conclusión general. El primero se refiere a las titulaciones femeninas; un 
profesor incluye un objetivo centrado en las personas, lo cual $3 / 4$ en ese marco general que hemos señalado $3 / 4$ estaría transgrediendo la concepción provisora de los objetivos asociada a su sexo.

P: Bueno, ¿̇consideras que les será útil a tus alumnos conocer lo que tú les explicas?

R: Sí, pero a dos niveles además. Yo siempre les digo que hay cosas que sirven para la profesión, y hay cosas que sirven para la vida. Y en el ámbito que nosotros trabajábamos, pues se dan las dos, las dos condiciones.

P: Y ¿ por qué les será útil?

$\mathrm{R}$ : Les será útil en la vida porque cuando estás hablando de comunicación, estás hablando de conocimiento, cuando estás [hablando] de aspectos de antropología básica, pues entonces estás hablando de cosas que afectan a las relaciones personales de estos individuos, a sus capacidades de interpretar las cosas, de comprender las relaciones humanas, y bueno, todo eso pues, claro, afecta a lo personal.

P: ¿Y a lo profesional?

$\mathrm{R}$ : Y a lo profesional igual porque claro, al igual que estamos diciendo que ayuda a comprender tus propias respuestas, reacciones, de los otros, no es más que generar un campo emocional compartido, a partir del cual tú tienes la capacidad de influir sobre el otro, respetándolo claro. Pero no es un aspecto de tecnología aplicada a un caso, eh?

(Reg. 3635-3640. Entrevista 6p: profesor de primer curso de Pedagogía).

Es decir, se señala no sólo la importancia de contribuir a las salidas profesionales del alumnado, sino también la importancia de impactar en cada persona, y con ello intentar singularizar el aprendizaje adecuándolo a las particularidades y necesidades de cada alumna, en tanto se propone como objetivo influir en sus vidas personales. El segundo matiz se refiere a las titulaciones masculinas; una profesora incluye un objetivo centrado en las cosas en función de las personas, lo que en ese marco general que hemos indicado, estaría transgrediendo la concepción provisora de los objetivos asociada al género de la titulación donde imparte docencia. Lo hace de un modo indirecto, a través de un ejemplo que elabora en su narración.

$\mathrm{P}:$ ¿Y consideras que la asignatura les será útil a tus alumnos?

R: Sí, totalmente, totalmente.

P: ¿̨or qué?

R: Porque un ingeniero en Informática tiene que saber... o sea, no es sólo diseñar algoritmos sino dado un problema que quieres resolver con un ordenador, has de saber desglosarlo en subproblemas, estructurarlo, analizarlo. Ver cuáles pros y cuáles contras tiene, ver qué casos posibles se pueden presentar y todo ello en esta asignatura se ve. $\mathrm{O}$ sea, de un problema que tienes, yo qué sé, tenemos un hospital que hay, con no sé cuantos doctores y vienen pacientes y tienes que analizar cómo puedes estructurar las listas 
de pacientes para intentar que todos los doctores atiendan, que cada paciente entre en la cola en la cual hay menos personas. A partir de este enunciado tienen que pensar qué estructura de datos tienes que utilizar, qué problemáticas se pueden dar. Es preciso listar por ejemplo que la cola de entrada esté vacía, cuál es la más llena, que hayan más o menos doctores, que se puedan añadir más doctores de una manera flexible, que se puedan añadir más pacientes de una manera flexible...

(Reg. 2024-2027. Entrevista 21p: profesora de primer curso de Ingeniería Informática).

Lo más evidente de esta cita es la orientación de la asignatura hacia lograr el objetivo de resolver problemas. El centro es la cosa. Y los recursos para resolver los problemas son de orden básicamente cognitivo. Sin embargo, el matiz lo introduce el ejemplo que menciona la entrevistada al plantear una situación donde hay personas que no son tomadas como meras cosas. La orientación a la cosa queda matizada por una finalidad última, difusa y que no necesariamente forma parte de los recursos para resolver el problema: el bienestar de las personas expresado en este caso a través de evitar esperas más allá de lo necesario. A pesar de que se trata de un matiz, cabe destacarlo porque es algo excepcional en los discursos expresados por las titulaciones más próximas a lo masculino.

En el caso del alumnado, las cosas son distintas. Hay que señalar que para este colectivo tenemos una limitación de datos que puede explicarse por los efectos del sexismo en la universidad que alcanza incluso el propio trabajo de campo. El alumnado de las titulaciones analizadas tiene una distribución sexista. Esto ha afectado a la posibilidad de realizar las entrevistas estructuradas al colectivo del alumnado hasta el punto de no lograr encontrar ningún alumno de Magisterio y Pedagogía dispuesto a ser entrevistado y ninguna alumna de Ingeniería Técnica Informática de Sistemas y de Ingeniería Informática.

Esta ausencia se compensó incrementando el número de entrevistas a las alumnas de Magisterio y Pedagogía y a los alumnos de Ingeniería Técnica Informática de Sistemas y de Ingeniería Informática. El efecto de esta operación es que las interpretaciones que realicemos sobre el impacto del género de las titulaciones en la objetivos expresados por el alumnado, y en general sobre las relaciones de cuidado y provisión en el contexto de las asignaturas, es limitado.

Como hemos señalado al principio, la salida profesional es uno de los objetivos que atribuyen y esperan lograr en su paso por la universidad y por las asignaturas. En este sentido, se orientan hacia la provisión, tomando al profesorado como, básicamente, provisores. Junto con ello, la obtención del título expresaría otro plano de provisión, en este caso más genérico, y que co- 
rrespondería a la dimensión credencialista de nuestra sociedad y que implícitamente se vincula con el mercado de trabajo o el desempeño de la profesión.

No podemos identificar grandes diferencias entre alumnas y alumnos a la hora de definir los objetivos vinculados a la formación en términos de cuidado y provisión, pero sí algunos matices. En cuanto a los objetivos centrados en las cosas, las alumnas expresan el aspecto ejecutivo del logro, es decir, conseguir el objetivo, en este caso, acabar la carrera; mientras que los alumnos señalan más bien el objeto del logro, es decir, los conocimientos en sí mismos. En todo caso están en el plano de la provisión y es donde sitúan los fines de la formación.

En este sentido parecería que el alumnado tanto si empieza la carrera como si la está acabando expresa objetivos formativos orientados hacia la provisión, lo cual podría ser un primer indicador de que las relaciones que experimenta en el contexto de las asignaturas en particular y de la carrera en general no están orientadas a modificar la posición provisora de partida, en todo caso las mantiene o refuerza.

De hecho es, como ya hemos indicado, algo que coincide de modo pleno con buena parte de los fines de las asignaturas más comunes entre el profesorado, sometidos también a una racionalidad instrumental evidente. Asimismo, encajan con los fines generales de la universidad, lo cual señala una sorprendente sintonía entre lo que requiere el mercado, el alumnado, el profesorado y la propia institución, que en este caso significa una posición provisora ante los fines de la formación. En este sentido, desde el punto de vista de los fines, parecería que, básicamente el fin es formar futuros provisores, sean mujeres u hombres y sobre ello parecería que habría una coincidencia generalizada.

Esto no significa que el alumnado no vincule a la formación objetivos centrados en las personas, pero podríamos calificar esos objetivos, en buena medida, como efectos colaterales de la actividad formativa, que en el caso del profesorado no son ni tan siquiera mencionados, pero que en el caso del alumnado toman una relevancia muy importante. Tanto alumnas como alumnos señalan como objetivos hacer amistades, disfrutar de la vida universitaria y personal de un modo distinto a como han vivido su anterior etapa formativa, los de primero con la emoción de la novedad y los de último curso con cierta nostalgia, como ilustran, respectivamente, las siguientes dos citas:

$\mathrm{P}:$ ¿Tú qué esperas de la universidad?

R: Espero pues vivir cosas que antes no había vivido, aprender todo lo que sea posible, porque es algo que estoy estudiando y que me gusta. Y no sé (-), de momento espero esto. Espero sorpresas (ja). 
(Reg. 12049-12050. Entrevista 2a: alumna de primer curso de Maestro. Especialidad en Educación Infantil).

$\mathrm{P}: \mathrm{Y}$ ¿qué esperas de la universidad?

R: El título (ja ja).

P: Básicamente.

R: Espero, espero ya poca cosa, ya me parece que todo cuanto me tenía que dar me lo ha dado. Si me vuelvo a... seguramente yo no dejaré nunca de estudiar, me gustaría no dejar de estudiar. Bueno, no sé si dejaré nunca de estudiar. Quiero decir que cuando acabe Derecho evidentemente buscaré un trabajo que esté relacionado con el Derecho y éste será realmente mi fuente de subsistencia, pero no lo sé, seguir estudiando, seguramente, seguiré estudiando. Pero ya no será lo mismo, ya no buscaré un primero. Ya no llegaré aquí y buscaré los niños de primero y a ver dónde vamos y qué hacemos este fin de semana. Porque me dirán: "Escucha, pero si tú tienes 36 años ėa dónde quieres ir este fin de semana? Con tu esposa y tus hijos tienes que ir me entiendes”, eso será la respuesta, supongo. Lo que me tenía que dar, ya considero que me lo ha dado y que aún me lo está dando. Aún me queda cuanto menos este final de curso, y este final de curso continúa siendo tan grande como el primero, el segundo, el tercero y el cuarto.

P: Y ¿qué es eso?

R: ¿Qué es? Es sobre todo compartir los finales de exámenes con la gente que no volverás a ver más porque acabas este año. Y el último examen con aquella gente son especiales, muy especiales, de hecho quiero decir, ya no lloremos ni por el examen, lloremos porque es el último y ya no volveremos a estar más con ellos, Ya no sé si nos volveremos a ver con mucha gente. Sí, somos amigos, somos grandes amigos pero hay muchas historias que a pesar de ser grandes amigos no continuarán. Está clarísimo eso. Y no es que me sepa mal, quiero decir, todo comienza y todo acaba. Lo que me sabe mal es yo continuaré estando aquí y ellos se marchen. Eso sí que me sabe mal. Con lo cual por eso tengo prisa por acabar.

(Reg. 14817-14822. Entrevista 16a: alumno de último curso de Derecho).

Adicionalmente, tampoco hay diferencias destacables entre alumnas y alumnos cuando se vincula, en escasas ocasiones, el impacto directo de la formación en la subjetividad de la persona como un fin. Es decir, cuando se toma la formación no sólo en términos de provisión sino como un tipo de contexto que permite al estudiante madurar como persona o progresar en el aprendizaje atendiendo a su singularidad. De hecho, el alumnado establece en escasas ocasiones un vínculo entre la formación que recibe en la universidad y su impacto en su formación como persona. Incluso cuando expresan que sienten que su formación universitaria no sólo les está preparando como futuros profesionales sino también como personas (especialmente señalado por el alumnado de primer curso), la noción de formación en ese nivel se 
delimita a la adquisición de conocimientos que podríamos calificar de uso personal, o lo que algunas personas entrevistadas etiquetan como "culturilla".

R: Hombre personal también, personal bueno yo he aprendido muchas cosa que a ver, son culturilla general, por ejemplo he aprendido de dónde viene el teletexto, por decirte algo. Que es una cosa que tú siempre... yo es que me hago muchas preguntas absurdas.

P: Sí.

R: Mi novia me lo dice constantemente. A lo mejor nos vamos a un sitio a cenar y digo yo y nos ponen una tostada de pan y digo yo, y que harán con el resto de rebanadas de pan, porque siempre te ponen la más grande.

P: Ya, ya.

$R: Y$ no, es que es un pan más grande, Pero bueno yo me lo pregunto todo. Pues por ejemplo lo que te digo, nos han explicado el teletexto, cómo funcionan los teléfonos móviles, cosas de ésas que a nivel personal que yo no voy a trabajar explicándole a la gente que es el teletexto.

P: Ya.

R: Pero a nivel personal pues sí, es culturilla que uno aprende, eso también.

(Reg. 10042-10048. Entrevista 20a: alumno de último curso de Ingeniería Técnica en Informática de Sistemas).

Las dimensiones ética y moral no son percibidas como un aspecto central que reciben o deberían recibir en su formación. Independientemente del sexo, la titulación y el nivel de curso, habría una amplia coincidencia en considerar que, sobre todo, lo que se recibe es una formación profesional, lo cual contribuiría a estrechar aún más el círculo entre lo que la universidad se propone formalmente, el profesorado ofrece y el alumnado recibe.

En este marco, básicamente provisor, podemos, sin embargo, señalar algunos matices: de crecimiento personal a través de lograr la madurez intelectual; y el reconocimiento de cierto impacto ético y moral mediante la cultura del sacrificio y del esfuerzo o de tomar conciencia de algunos de los límites que marcan la vida personal como ilustra la siguiente cita:

P: Lo que estudias, ¿̇crees que tiene que ver con tu formación profesional o más bien con tu formación como persona?

R: Las dos cosas. Sí, da formación profesional evidentemente (-) y como persona, porque te hace concienciarte de cosas que no tenías ni idea. Yo qué sé, el hecho de hojear los textos legales que tenemos, es que por la tele... claro no te dicen nada pero hay artículos y cosas que dices "qué barbaridad, cómo está esto aquí, cómo no lo han cambiado aún" y sin haber entrado en esta carrera o cualquier otra que toque estos temas no te enteras, no te empapas de nada, y claro que tomas una dinámica de pasotismo. Como no lo sabes y lo desconoces, pues no le das importancia. Claro cuando lo sabes 
y eso puede afectar a tu vida luego ya reaccionas. (-) Sobre todo en temas de seguridad social: de viudedad, pensión de jubilación, de orfandad, lo que te pasaría, qué posibilidades tienes, la de cosas que pueden reclamar las personas y no lo hacen porque no lo conocen. Y eso sí que se tendría que impulsar.

P: ¿Y cómo crees que te ha cambiado que estudiaras esta carrera? A nivel personal.

R: Eso. Concienciarme más, yo sabía que habían cosas que... ¿̇sabes? están ahí. Como no lo sabes bien pues no le das importancia. A medida que lo vas estudiando y vas profundizando más... te das cuenta y dices "la de cosas que hay que cambiar". Sí, sí, sobre todo cambiar porque es muy importante el cambio ya sabía que... es bueno cambiar. Pero cuando te metes en esta carrera las personas no se pueden acomodar, tienen que ir reciclándose y no sólo en su trabajo sino en su vida diaria. Leer el periódico, ponerse al día de las cosas.

P: Te diste cuenta en primero. O sea, empezó a cambiar en ese sentido en primero.

R: Sí, sí.

(Reg. 13703-13708. Entrevista 11a: alumna de último curso de Relaciones Laborales).

La formación de la persona queda, pues, en un segundo plano e incluso parecería para algunas personas entrevistadas algo difícil de lograr. Las razones, en este punto, varían. En un caso se señala la imposibilidad de lograrlo debido a que no hay un contexto adecuado. Este sería el de un uso intensivo de las tutorías, no sólo para resolver dudas sobre los contenidos de la asignatura, sino sobre cuestiones más generales y transversales, lo cual daría pie a incidir en los aspectos más personales de las y los estudiantes.

En otros casos se apunta a que se trata de cualidades predeterminadas en las cuales la actividad formativa universitaria tiene poco qué hacer. En este caso se sitúa como un elemento central del argumento la necesidad que a uno le guste la actividad para poder llevarla a cabo. Habría una cierta lectura esencialista: una persona hace o estudia algo porque le gusta. No le gusta lo que hace por el hecho de hacerlo. Las cualidades vendrían a ser una precondición, sobre las cuales da a entender la entrevistada poco hay que hacer. Parece que todo indica que la disposición del alumnado en cuanto a los fines asociados a la formación es básicamente provisora, donde la actividad formativa universitaria si no contribuye a ello, en todo caso lo reafirma.

\section{Conclusiones}

El análisis de los discursos del profesorado y del alumnado sobre los componentes de cuidado y de provisión en la concepción de los fines de las asignaturas nos permite señalar algunas características básicas de las interacciones 
entre docentes y estudiantes. En primer lugar, hay un denominador común entre profesorado, alumnado y la propia institución: el objetivo de suministrar una formación cuyos contenidos sean adecuados al mercado de trabajo.

El profesorado se construye como principal proveedor de esos conocimientos orientados a la atención de las necesidades del mercado de trabajo y de las empresas. Sin embargo, como hemos visto, los puntos comunes se acaban aquí. De ese objetivo, el alumnado entrevistado de algún modo parece demandar una mayor eficacia en el logro de ese objetivo provisor, desatendiendo otras posibles finalidades que debiera cumplir la universidad.

En este sentido, su vínculo parece especialmente instrumental, hasta el punto de no percibir lo que es un efecto no explícito que acompaña el objetivo que el profesorado se plantea cuando se propone formar de la mejor manera posible a su alumnado: cuidarlo al fomentar su autonomía, aunque no se lo plantee, en la mayoría de los casos, como un objetivo explícito a lograr. Sin embargo, tampoco el profesorado, en términos generales, expresa de forma clara la asociación entre la formación adecuada al mercado y sus efectos sobre apoyar el desarrollo de la autonomía del alumnado.

Es más, la concepción de los fines es, en este punto, ciega a toda reflexividad. De algún modo se toma como algo que es evidente por sí mismo. Quizás habría que reflexionar individual o colectivamente más sobre los objetivos de las asignaturas y de las titulaciones en general, teniendo en cuenta de forma explícita dónde quedan las necesidades del alumnado y como éstos pueden tomar conciencia de ellas. Quizás una forma de apoyar el desarrollo de la autonomía del alumnado puede empezar por estimular la reflexividad sobre sus propias necesidades y poderlas expresar, y no tomarlas exclusivamente como un objeto que viene definido y delimitado por el profesorado.

La escasa referencia a elementos que conecten con el cuidado por parte del alumnado en cuanto a fines de las asignaturas, independientemente del sexo, la titulación y el curso, nos avisa de un escaso reconocimiento de la propia fragilidad y de la fragilidad ajena, de la dependencia y del reconocimiento de las propias necesidades y de su satisfacción. Que una persona espere de la universidad, de sus estudios, de las asignaturas mejorar su conjunto de oportunidades en el mercado de trabajo es un objetivo razonable.

Sin embargo, que sea el único objetivo académico preferente es indicador de que no se busca el desarrollo o autonomía de la propia persona, y si esto se alcanza lo es en cuanto efecto colateral de lograr adecuar las personas al mercado de trabajo. Esta concepción compartida entre profesorado y alumnado, independientemente del sexo y de la titulación, pone el acento en 
la provisión con ello a un marcado sesgo de género de los fines de la formación universitaria, que prima una concepción masculina de la misma.

En este sentido, el marco general y compartido de la universidad, según como interpretamos los discursos de las personas entrevistadas, presiona hacia una dirección, cegando la importancia de incorporar en los fines de las asignaturas la dimensión del cuidado, y con ello una concepción femenina de los fines. El elemento más evidente de esta ausencia es que no forma parte de los contenidos de las asignaturas tener en cuenta en el desempeño de las profesiones el impacto que tiene su actividad sobre las personas. No hemos detectado en los discursos de ningún entrevistado una orientación de este tipo. Más bien todo lo contrario.

Desde el punto de vista de las diferencias en el discurso del profesorado según sexo y titulación, hemos podido mostrar que el efecto de ambas variables no es simétrico. Señalamos que las profesoras, en términos generales, son más sensibles al contexto de las titulaciones, incluso para dejar de plantear objetivos vinculados al cuidado para pasar a la provisión, confirmando, paradójicamente, la disposición al otro de las mujeres.

Mientras, los profesores expresan objetivos vinculados con la provisión en todas las titulaciones. Es decir, las profesoras de las titulaciones más próximas a lo femenino cumplen con la expectativa de género asignado socialmente a su sexo, al prestar atención especialmente a las personas. Pero no ocurre lo mismo con las profesoras de las titulaciones más próximas a lo masculino, las cuales rompen con la expectativa de género asignado a su sexo al adoptar como finalidad objetivos centrados en las cosas, es decir, en priorizar el aprendizaje de los contenidos.

Esto parecería señalar que el género de las titulaciones incidiría más que el sexo sobre el profesorado. Parecería que las titulaciones femeninas no tienen el mismo impacto en los hombres que las titulaciones masculinas en las mujeres. En el caso de las profesoras parece obedecer básicamente al género de las titulaciones en cuanto a fines formativos, sin apenas diferencias si se trata de diplomaturas o de licenciaturas, y en el caso de los profesores a los imperativos de su sexo.

Parecería, pues, necesario, para poder reducir el sesgo de género de los fines de la docencia universitaria, introducir en sus planes formativos competencias vinculadas con el cuidado, así como revisar cuáles de los actuales fines de la formación universitaria responden a las necesidades del alumnado, y no sólo a sus demandas que parecen, a menudo, las únicas atendidas. 
Convergencia Revista de Ciencias Sociales, núm. 70, 2016, Universidad Autónoma del Estado de México

\section{Bibliografía}

Boltanski, Luc (2000), El amor y la justicia como competencias, Buenos Aires: Amorrortu.

Bubeck, Diemut E. (1995), Care, Gender and Justice, New York, USA: Oxford University Press.

Butler, Judith (2001), El género en disputa. El feminismo y la subversión de la identidad, México: Paidós.

Butler, Judith (1990), "Variaciones sobre sexo y género. Beauvoir, Wittig y Foucault", en Seyla Benhabib y Drucilla Cornell, Teoria feminista y teoría crítica, Valencia: Ediciones Alfons el Magnanim.

Clair, René [ed.] (1996), La formación cientifica de las mujeres. ¿Por qué hay tan pocas cientificas?, Madrid: Los Libros de la Catarata.

Contreras Domingo, José (1990), Enseñanza, curriculum y profesorado, Madrid: Akal.

Curráis Porrúa, Juan y Margarita Pérez-Froiz (1995), "Pensar la educación desde la ética: exilio y retorno de la razón práctica”, en Estudios. Filosofía-historia-letras, núm. 39-40, México: Instituto Tecnológico Autónomo de México.

Dale, Mary y Lewis Jane (2000), “The concept of social care and the analysis of contemporary welfare states", en British Journal of Sociology, vol. 51, núm. 2, London: London School of Economics.

Duarte, Laura (2012), Condicionantes de la trayectoria académica y del acceso a las cátedras en la institución universitaria desde la perspectiva de la movilidad ocupacional, la orientación profesional y el sexo. Estudio de caso de la Universitat Autonoma de Barcelona, tesis de doctorado, Barcelona: Universitat Autònoma de Barcelona.

Ehrenreich, Barbara y Airle Russell Hochschild [eds.] (2003), Global Woman: Nannies, Maids, and sex workers en the new economy, New York: Metropolitan Books.

ETAN Expert Working Group on Women and Science (2000), Science Policies in the European Union: Promoting Excellence Through Mainstreaming Gender Equality, European Commission Research: Directorate-General.

Fraise, Geneviève (2000), "Servidumbre, empleos de servicios y de democracia”, en Maruani, Margaret et al. [eds.], Las nuevas fronteras de la desigualdad, Barcelona: Icaria.

Foucault, Michel (1998), Historia de la sexualidad, 3 vols., Madrid: Siglo XXI.

Fox, Mary Frank (1995), "Woman and Scientific Careers", en Handbook of Science and Technology Studies, London: Sage.

Fox, Mary Frank (2004), Women in Scientific Fields: Doctoral Education and Academinc Careers. Workshop on Women's Advancement, New York: American Political Science Association.

Fox, Mary Frank y Stephan, Paula E. (2001), “Careers of Young Scientists. Gender”, en Social Studies of Science, vol. 31, núm. 1, London: Sage.

Giroux, Henry A. (1990), Los profesores como intelectuales. Hacia una pedagogía crítica del aprendizaje, Madrid: Paidós-MEC. 
González, María Teresa, Pérez, Manuel y Fernández, Manuel (1995), Trayectorias ocupacionales de los becarios de investigación españoles (1982-1992), Madrid: Consejo Superior de Investigaciones Científicas, Instituto de Estudios Sociales Avanzados.

Hochschild, Arlie Russell (2012), The Outsourced Self: Intimate Life in Market Times, New York: Metropolitan Books.

Hochschild, Arlie Russell (2008), La mercantilización de la vida intima, Madrid: Katz.

Horkheimer, Max (2002), Critica de la razón instrumental, Madrid: Trotta.

Iñiguez, Lupicinio (2005), Análisis del Discurso. Manualpara las Ciencias Sociales, Barcelona: Universitat Oberta de Catalunya.

Izquierdo, María Jesús, Enrico Mora y Laura Duarte (2008), Cuidado y provisión: el sesgo de género en las prácticas universitarias y su impacto en la función socializadora de la universidad, Madrid: Ministerio de Igualdad, Instituto de la Mujer.

Izquierdo, María Jesús, Francisco José León y Enrico Mora (2008), “Sesgo de género y desigualdades en la evaluación de la calidad académica”, en Arxius de Ciències Socials, núm. 19, València: Universitat de València.

Izquierdo, María Jesús (2007), "Lo que cuesta ser hombre: costes y beneficios de la masculinidad”, en Ponencias del Congreso Masculinidady vida cotidiana, Gasteiz, España: Emakunde y Comunidad Europea/Fondo Social Europeo.

Izquierdo, María Jesús [dir.] et al. (2004), El sexisme a la UAB. Propostes d'actuació i dades per a un diagnostic, Barcelona: Servei de Publicacions de la Universitat Autònoma de Barcelona.

Izquierdo, María Jesús (2001), Sin vuelta de hoja. Sexismo: poder, placer y trabajo, Barcelona: La Biblioteca del Ciudadano.

Izquierdo, María Jesús [dir.] et al. (1999), El sexisme a la universitat. Estudi comparatiu del personal assalariat de les universitats públiques catalanes, Barcelona: Servei de Publicacions de la Universitat Autònoma de Barcelona.

Jecker, Nancy S. y J. Donnie Self (1991), "Separating Care and Cure: An Analysis of Historical and Contemporary Images of Nursing and Medicine", en The Journal of Medicine and Philosophy, vol. 16, núm. 3, Oxford: Oxford University Press.

Ledwith, Sue y Simonetta Manfredi (2000), "Balancing gender in higher education. A study of the experience of senior women in a 'new' UK university”, en The European Journal of Women's Studies, núm. 7, London: London School of Economics and Political Science.

Long, J. Scott y Mary Frank Fox (1995), “Scientific careers: universalism and particularism”, en Annual Review of Sociology, núm. 21, California: Annual Reviews.

Maruani, Margaret et al. (2000), Las nuevas fronteras de la desigualdad. Hombres y mujeres en el mercado de trabajo, Barcelona: Icaria.

Martín Rojo, Luisa (2003), “El análisis crítico del discurso”, en Iñiguez, Lupicinio et al. [comps.], Análisis del Discurso, Barcelona: Universitat Oberta de Catalunya.

Mora, Enrico y León Francisco (2011), "La globalización del cuidado y sus cadenas", Psicoperspectivas, vol. 10, núm. 2, Chile: Pontificia Universidad Católica de Valparaíso. 
Convergencia Revista de Ciencias Sociales, núm. 70, 2016, Universidad Autónoma del Estado de México

Mora, Enrico y Margot Pujal (2010), “Los conceptos de cuidado, provisión, y servicio como herramientas de análisis de las relaciones de género", en X Congreso Español de Sociología, Pamplona, España, del 1 al 3 de julio de 2010.

Mora, Enrico (2006), "Los componentes de cuidado y servicio cuando se globaliza el trabajo doméstico”, en Izquierdo, María Jesús et al. [eds.], Servidoras sin fronteras, Barcelona: Fundació Jaume Bofill.

Mora, Enrico (2005), "Patriarcado, capitalismo y clases sociales”, en Joaquín Giró Miranda [coord.], El género quebrantado: sobre la violencia, la libertad y los derechos de la mujer en el nuevo milenio, Madrid: Catarata.

Mora, Montserrat (2002), "La cura familiar de les persones grans", en Revista Catalana de Sociologia, vol. 16, Barcelona: Associació Catalana de Sociologia.

Orozco, Amaia (2007), Cadenas globales de cuidado, Santo Domingo: INSTRAW.

Ortiz, Teresa y Gloria Becerra [eds.] (1996), Mujeres de ciencias: mujer, feminismo y ciencias naturales, experimentales y tecnológicas, Granada: Universidad de Granada y Instituto de Estudios de la Mujer.

Osborn, Mary et al. (2000), Science Policies in the European Union: Promoting Excellence Through Mainstreaming Gender Equality. A Report from the ETAN Expert Working Group on Women and Science, Luxembourg: Office for Official Publications of the EC.

Parker, Ian (1992), Discourse dynamics, London: Routledge.

Pérez, Pilar y Susana Andino (2003), Las desigualdades de género en el sistema público universitario vasco, Vitoria-Gasteiz: Emakunde.

Potter, Jonathan y Margaret Wetherell (1987), Discourse and social psychology: Beyond Attitudes and Behavior, London: Sage.

Radl, Rita María [ed.] (1996), Mujeres e institución universitaria en Occidente, Santiago de Compostela: Universidad de Santiago de Compostela.

Rifa-Valls, Montserrat y Laura Duarte (2013), “Interseccionalidades de género, desigualdad y educación superior. Categorías y estrategias en la investigación”, en Martha Zapata, Sabina García y Jennifer Chan [eds.], La interseccionalidad en debate: Actas del Congreso Internacional: Indicadores Interseccionales y Medidas de Inclusión Social en Instituciones de Educación Superior, Berlín: MISEAL.

Rees, Teresa (2002), National Policies on Women and Science in Europe, European Commission Research: Directorate-General.

Rossi, Alice S. (1965), “Women in Science: Why so Few ?”, en Science, núm. 148, Washington, DC: American Association for the Advancement of Science,

Ruiz Olabuénaga, J. Ignacio y María Antonia Ispizua (1989), La decodificación de la vida cotidiana. Métodos de investigación cualitativa, Bilbao: Universidad de Deusto.

Schön, Donald A. (1992), La formación de profesionales reflexivos, Madrid: Paidós-MEC.

Setién, María Luisa (1998), "Género y cuidado a las personas en el espacio doméstico", en Inguruak, Revista Vasca de Sociología y Ciencia Politica, núm. 22, Bilbao España: Asociación Vasca de Sociología y Ciencia Política. 
Sevenhuijsen, Selma (2000), "Caring in the Third Way: The Relation between Obligation, Responsibility and Care in Third Way Discourse”, en Critical Social Policy, vol. 20, núm. 1, London: Sage.

Simpson, Ruth (2004), "Masculinity at work: the experiences of men in female dominated occupations", en Work, employment and society, vol. 18, núm. 2, London: Sage.

Taylor, Steven J. y Robert Bogdan (2000), Introducción a los métodos cualitativos de investigación. La búsqueda de significados, Barcelona: Paidós.

Torns, Teresa et al. (2004), "La conciliación de la vida laboral y familiar: ¿un horizonte posible?”, en Sociología del Trabajo, núm. 50, Madrid: Siglo XXI.

Thompsom, Suzane (2002), "Caregivers of Stroke Patient Family Members: Behavioral and Attitudinal Indicators of Overprotective Care”, en Psychology and Health, vol. 17, núm. 3, London: Sage.

Universitat Autònoma de Barcelona (2003), Estatuts de la Universitat Autónoma de Barcelona, Barcelona: Diari Oficial de la Generalitat de Catalunya (Decret 237/2003, de 8 de octubre).

Van Verken, Mieke e Itziar Hernández (1989), Mujeres, tecnología y desarrollo, Madrid: Ministerio de Asuntos Sociales e Instituto de la Mujer.

Vázquez-Cupeiro, Susana (2015), Ciencia, estereotipos y género: una revisión de los marcos explicativos, en Convergencia Revista de Ciencias Sociales, núm. 68, México: Universidad Autónoma del Estado de México.

Vázquez, Félix (1996), "El análisis de contenido temático", en Vázquez, Félix, Objetivos y medios en la investigación psicosocial, Barcelona: Working Paper, UAB.

Vega Solís, Cristina (2009), Culturas del cuidado en transición: Espacios, sujetos e imaginarios en una sociedad de migración, Barcelona: UOC.

Wittig, Monique y Sande Zeig (1981), Borrador para un diccionario de las amantes, Barcelona: Lumen.

Wittig, Monique (1977), El cuerpo lesbiano, Valencia: Artes Gráficas Soler.

\section{Recurso electrónico}

Pérez Sedeño, Eulalia et al. (sin fecha), Mujer y Ciencia. La situación de las mujeres investigadoras en el sistema español de ciencia y tecnología, Informe, Madrid: FECYT. Disponible en: http://www.oei.es/salactsi/mujer_ciencia.pdf [13 de agosto de 2015].

Enrico Mora. Doctor en Sociología, profesor del Departamento de Sociología de la Universitat Autònoma de Barcelona, España. Líneas de investigación: análisis de las desigualdades sociales y del poder según las relaciones de sexo, género y de clase en el ámbito del trabajo (mercantil y doméstico) y de la salud, y su impacto, por un lado, en la formación de las subjetividades, las emociones y los cuerpos, y por otro, en las relaciones sociales de cuidado y provisión. Publicaciones recientes: Mora, Enrico, "Las circunstancias en la 
acción. Institucionalización, acomodación y resistencia en el capitalismo patriarcal”, en Revista Internacional de Ciencias Sociales Interdisciplinares, vol. 4, núm. 2 (2015); Pujal i Llombart, Margot y Enrico Mora, "Subjectivity, health and gender: an approach to chronified pain through the Psychosocial gender Diagnostic methodology", en Studies in Psychology, vol. 35, núm. 2 (2014); Mora, Enrico, "La organización social y de género del grito. Quien puede gritar en un gimnasio", en Prisma Social, Revista de Ciencias Sociales, núm. 13 (2014).

Margot Pujal i Llombart. Doctora en Psicología Social, profesora del Departamento de Psicología Social de la Universitat Autònoma de Barcelona, España. Líneas de investigación: salud, género, subjetividad y cuerpo; análisis psicosocial de violencias de género. Publicaciones recientes: Arensburg, Svenska y Pujal y Llombart, Margot, "Aproximación a las formas de subjetivación jurídica en mujeres víctimas de violencia doméstica", en Revista Universitas Psycologica, vol. 13, núm. 4 (2014); Pujal i Llombart, Margot y Enrico Mora, "Subjectivity, health and gender: an approach to chronified pain through the Psychosocial gender Diagnostic methodology", en Studies in Psychology, vol. 35, núm. 2 (2014); Schongut, Nicolas y Pujal i Llombart, Margot, "Intertextualidad y narratividad como herramientas para el ejercicio de la reflexividad en la investigación feminista: el caso del dolor y el género", en Athenea Digita, vol. 14, núm. 4 (2014).

Recepción: 16 de octubre de 2014.

Aprobación: 7 de septiembre de 2015. 